\title{
A BUSCA DA PROFISSIONALIDADE DA DOCÊNCIA NO ENSINO SUPERIOR
}

\author{
Marinalva Lopes Ribeiro' \\ Jefferson da Silva Moreira²
}

\section{RESUMO}

Alinhados ao movimento de profissionalização da docência, apresentamos, neste texto, resultados de uma pesquisa-ação colaborativa, de abordagem qualitativa, realizada numa instituição de Educação Superior pública do interior do Estado da Bahia, cujo objetivo foi conhecer as representações de professores-pesquisadores sobre a profissão docente. Considerados produtores de conhecimento sobre as suas próprias práticas educativas, os docentes têm se implicado nesse processo formativo, de forma espontânea. Os dados tomados como corpus de análise foram coletados em reuniões de formação, que acontecem quinzenalmente, no próprio locus de trabalho dos professores. Contribuições de Tardif (2009), Soares e Cunha (2010), Carbonneau (2006), Bourdoncle (2006), D'Ávila e Soneville (2008) e Rios (2009) deram a principal sustentação teórica para a interpretação dos dados produzidos. Para análise desse material, aproximamo-nos da técnica de análise de conteúdo de Bardin (2006). A análise dos dados produzidos no primeiro ano desta pesquisa indicam que os professores exercem a profissão intuitivamente, sem o domínio dos conhecimentos didáticos e pedagógicos. Assim, a profissão docente, no ensino superior, vai sendo construída mediante a socialização profissional e a troca de experiência com os pares. Os resultados sinalizam fragilidades na

1 Professora do Departamento de Educação da Universidade Estadual de Feira de Santana. Coordenadora do Núcleo de Estudos e Pesquisas sobre Pedagogia Universitária (NEPPU). Ph. D. em Educação pela Universidade de Sherbrooke, Canadá. E-mail: marinalva_biodanza@ hotmail.com

2 Licenciatura em Pedagogia pela Universidade Estadual de Feira de Santana. Bolsista de iniciação científica pelo Conselho Nacional de Desenvolvimento Científico e Tecnológico (CNPq). Membro do Núcleo de Estudos e Pesquisas sobre Pedagogia Universitária (NEPPU). E-mail: moreirajefferson92@yahoo.com.br. 
profissionalidade docente dos colaboradores da pesquisa, aspectos que podem estar atrelados a não existência de uma política de formação e desenvolvimento profissional para os docentes da Educação Superior. Todavia, com a participação nesta pesquisa-ação colaborativa, os professores têm tido oportunidade de refletir sobre suas práticas, teorizar sobre elas e experimentar inová-las, o que nos anima a continuar avançando nesse processo de desenvolvimento profissional.

Palavras-chave: Profissão Docente. Pesquisa-ação colaborativa. Profissionalidade.

\section{LOOKING FOR TEACHING PROFESSIONALISM IN UNDER-GRADUATE EDUCATION}

\section{ABSTRACT}

Aligned to the teaching professionalization movement, we present in this text, results of a collaborative action research, with a qualitative approach, performed at a public higher education institution in the state of Bahia, Brazil. It aims to a better understandingonthe professorsresearchers' representations about the teaching career. Regarded as producers of knowledge about their own educational practices, professors have been involved spontaneously in this formative process. Data taken for the analysis set was collected in training meetings, which take place at every two weeks, at the professors' own working locus. Contributions from Tardif; Soares and Cunha; Carbonneau; Bourdoncle; D'Avila and Soneville; Rivers and Enguita, gave the main theoretical framework for the interpretation of the data produced. For the analysis, we approached Bardin's (1977) content analysis technique. Analyzing the data produced in the first year of this research, we came up with the conclusion that the professor sactintuitively, having no domain of didactics or pedagogy. Thereby, the teaching profession for higher education is being built by professional socialization and exchange of experience among pairs. The results indicate some weakness in the 
teaching profession, aspects that may be linked to a lack of training policies, and professional development for these professors. However, with the participation in this collaborative action research, professors have had the opportunity to reflect on their own practice, to theorize about it, and to experience innovatingthem. This encourages us to continue moving forward in this process of professional development.

Keywords: Teaching Profession. Action research collaborative. Professionalism.

\section{LA BÚSQUEDA DE PROFESIONALIDAD DE LA DOCENCIA EN LA ENSEÑANZA SUPERIOR}

\section{RESUMEN}

Alineados con el movimiento de profesionalización docente, presentamos, en este texto, resultados de una investigación - acción colaborativa, de enfoque cualitativo, realizado en una institución de Educación Superior pública en el Estado de Bahía, que tiene como objetivo conocer las representaciones de profesores investigadores sobre la profesión docente. Considerados productores de conocimiento sobre sus propias prácticas educativas, los profesores tienen implicado en este proceso formativo, de forma espontánea. Los datos tomados para análisis se recogieron en reuniones de formación, que tienen lugar a cada quince dias, en el próprio locus de trabajo de los maestros. Contribuciones de Tardif ( 2009 ), Soares y Cunha ( 2010 ), Carbonneau ( 2006 ), Bourdoncle ( 2006 ), D’Ávila y Soneville ( 2008 ) y Ríos ( 2009 ) dieron el principal soporte teórico para la interpretación de los datos producidos. Para el análisis de este material, nos acercamos a la técnica de análisis de contenido de Bardin (2006). El análisis de los datos producidos en el primer año de esta investigación indican que los maestros ejercen la profesión de manera intuitiva, sin el dominio de los conocimientos didácticos y pedagogicos. Así, la profesión docente, en la enseñanza superior, está siendo construida por la socialización profesional y el 
cambio de experiencias con sus compañeros. Los resultados indican fragilidad en la profesionalidad docente de colaboradores de la investigación, aspectos que pueden estar vinculados a falta de una política de formación y desarrollo profesional para los profesores de la Enseñanza Superior.Todavía, con la participación en esta investigación acción colaborativa, los maestros han tido la oportunidad de reflexionar sobre sus prácticas, teorizar a respecto de ellas y experimentar hacer innovaciones, lo que nos anima a seguir avanzando en este proceso de desarrollo profesional.

Palabras clave: Profesión Docente. Investigación-acción colaborativa. Profesionalidad.

\section{Introdução}

Na atualidade, diversas são as transformações econômicas, sociais, tecnológicas e culturais que se proliferaram por todo o mundo, influenciadas pelos processos de globalização. Tais aspectos impactaram diretamente as diversas profissões, ocasionando uma verdadeira crise quanto aos papéis tradicionais que elas desempenharam ao longo da história da humanidade (D. SOBRINHO, 2009). Na chamada "era da comunicação", computadores sofisticados, robótica e outras tecnologias não apenas aperfeiçoam os processos, mas mudam as relações sociais, a concepção de trabalho, exigindo dos indivíduos um novo perfil que ultrapasse os conhecimentos técnicos e específicos de cada profissão. Assim, eles têm que desenvolver uma série de habilidades pessoais: iniciativa, criatividade, liderança, trabalho em equipe, dentre outras. Evidentemente, o professor universitário, responsável pela formação de tais profissionais, está sendo instigado a mudar a sua prática docente, para que esteja alinhada concomitantemente a essas novas demandas e ao perfil de estudante que tem adentrado na universidade, a partir das políticas de expansão da educação superior que estão em vigor no Brasil a partir do governo do Presidente Lula.

Dados divulgados pelo Ministério da Educação (MEC) 
revelam que, de 2005 a 2015, o número de universidades federais passou de 51 para 63, nos diversos Estados brasileiros, ampliando, desse modo, as possibilidades e as formas de ingresso dos estudantes (BRASIL, 2014).

Em que pese as críticas no que diz respeito à precariedade de políticas que garantam a permanência dos estudantes, a partir de 2003, foram criadas e ampliadas várias políticas de acesso ao ensino superior que objetivam reparar, mesmo que timidamente, desigualdades sociais históricas, tais como o Programa Universidade para Todos (PROUNI), o Fundo de Financiamento Estudantil (FIES), além das políticas afirmativas que reservam vagas para estudantes negros, indígenas, quilombolas e provenientes de escolas públicas.

É inegável que o perfil dos estudantes mudou. Muitos são provenientes dos mais baixos estratos sociais; há aqueles que entram na sala de aula depois de um dia de trabalho cansativo; há estudantes imaturos que preferem matar aula para estarem plugados no whatsapp; muitos deles apresentam grande lacuna em conhecimentos básicos, essenciais para o desenvolvimento de atividades intelectuais mais complexas. Nesse sentido, é fundamental que os professores sejam capazes de desenvolver estratégias para motivá-los, acolhê-los, envolvê-los nas atividades acadêmicas e desenvolver habilidades operatórias diferenciadas.

Evidentemente, tais ações dependem de condições contextuais e de uma formação voltada para o desenvolvimento profissional dos professores que atuam na Educação Superior, sem a qual eles vão realizando o seu ofício na sala de aula de forma leiga, muitas vezes a partir de um esforço hercúleo, sem garantia de uma aprendizagem duradoura por parte dos estudantes, quer dizer uma aprendizagem que seja transferível para novos contextos e situações de vida.

Todavia, em consequência do silenciamento dos dispositivos normativos (Lei de Diretrizes e Bases da Educação Nacional 9394/96; V Plano Nacional de Pós-Graduação - PNPG 2011-2020) acerca da exigência da formação específica para a docência universitária, bem 
como da cobrança da Coordenação de Aperfeiçoamento de Pessoal de Nível Superior (CAPES) por produção resultante de pesquisas, os saberes pedagógicos e didáticos não têm sido exigidos na formação nem em processos de seleção e progressão na carreira dos professores, fazendo com que a docência seja entendida e praticada de forma não profissional, como se bastasse, somente, para o seu exercício, o domínio dos conteúdos específicos da área em que esse sujeito se graduou e especializou, muitas vezes, em estudos doutorais e pós-doutorais.

Diante dessa problemática, torna-se indispensável, na atualidade, que se planeje a criação de um conjunto de ações sistemáticas que visem transformar as crenças, representações e práticas dos professores a partir da reflexão com os próprios pares sobre os desafios do cotidiano da sala de aula e a criação de estratégias para superá-los. Nesse sentido, desenvolvemos uma pesquisa-ação colaborativa, cujos resultados serão apresentados neste trabalho.

Profissionalização e profissionalidade docente: elementos que se entrecruzam

As palavras de Freire (1997, p.32), “[...] a prática educativa não deve ser uma espécie de marquise sob a qual a gente espera a chuva passar. E para passar uma chuva numa marquise não necessitamos de formação", apontam elementos relevantes para analisarmos a lacuna historicamente constituída no cenário da formação específica para o exercício da docência na Educação Superior. Legitimadas numa perspectiva profissional, as práticas educativas não devem se constituir em um laissez-faire, mas precisam ser orientados por um conjunto de conhecimentos, fundamentos e saberes próprios que a validem.

$\mathrm{Na}$ atualidade, em decorrência de um intenso movimento pela profissionalização da docência, iniciado na América do Norte, essa atividade tem assumido certas características de uma profissão liberal, como autonomia, competência e o exercício de atividades mais complexas, passando a alcançar um status que a diferencia meramente 
de um ofício. O que se pretende é que a profissão de professor alcance o mesmo patamar de outras profissões já consolidadas, ainda que tenha suas próprias especificidades (BOURDONCLE, 2006; CARBONEAU, 2006; TARDIF, 2009; SOARES; CUNHA, 2010).

No entanto, o conceito de profissão é complexo e não possui um significado consensual entre os diversos estudiosos, variando para cada autor as características e os aspectos próprios que a define. Diante de tamanha abrangência, optamos por definir o exercício da atividade docente como uma profissão possuidora de especificidades e características próprias.

No sentido etimológico, o termo profissão deriva do verbo latino professione, cujo significado é declaração ou ofício. No intuito de identificarmos mais detalhadamente o seu sentido, recorremos ao Dicionário de Sociologia que define ser a profissão uma "[...] atividade especializada, normalmente exercida por pessoas com curso universitário e altamente qualificada do ponto de vista profissional" (JOHNSON, 1997, p. 89).

A Enciclopédia de Pedagogia Universitária define a profissão docente como a

Posse de um repertório que inclui conhecimentos (knowledge base), estratégias e técnicas profissionais por meio das quais a profissão procura solucionar situações problemáticas concretas e padrões de competência fixados para a formação dos professores e a prática do magistério. (MOROSINI, 2006, p. 395).

Assim, podemos perceber que os diversos sentidos atribuídos ao termo profissão, a partir de diferentes perspectivas, ressaltam a necessidade de conhecimentos profissionais, competências, profissionalismo, ética, dentre outros aspectos que a distingue de uma ocupação.

O termo profissão designa, ainda, uma atividade específica e complexa, e por isso, ela é sempre realizada por pessoas competentes, com um profundo domínio dos conhecimentos que caracterizam 
o seu metier, possuidores de uma identidade e princípios éticos em comum. Destarte, para que uma atividade seja considerada profissão, é necessária uma formação especializada, autonomia e colegialidade nos processos de tomada de decisões que dizem respeito às características dessa profissão. Ou seja, é indispensável uma integração coletiva dos profissionais acerca dos processos e deliberações sobre aspectos que dizem respeito aos assuntos que os associa (D'ÁVILA; SONEVILLE, 2008).

No campo Sociológico, o conceito de profissão tem sido comumente utilizado para se referir às profissões liberais clássicas, dentre as quais se destacam a Medicina, a Engenharia, o Direito - que ganharam ao longo da história da humanidade um status superior a outras ocupações pelas suas características e singularidades diferenciadoras no que se refere à autonomia profissional; possuindo, assim, estatuto que Ihes garantem maior independência, se comparada a outras ocupações.

Notamos que algumas características em comum fundamentam os diversos estudos e pesquisas sobre as profissões, o que permite estabelecer alguns parâmetros específicos sobre a sua natureza. Estudiosos do campo da profissionalização docente, tais como Carbonneau (2006) e Bourdoncle (2006) destacam distinções que tornam possível diferenciar uma profissão de um ofício ou ocupação, a saber: a primeira característica é o profundo domínio de um conjunto de conhecimentos, saberes, ações e conhecimentos complexos sistematizados que se traduzem na oferta de um serviço especializado e/ou produto aos agentes da sociedade. Uma profissão tem a garantia de um conjunto de conhecimentos profissionais próprios que somente é dominado pelos indivíduos que a exercem.

A segunda característica refere-se à formação do profissional, visto que, uma profissão, diferentemente de um ofício e/ ou ocupação, caracteriza-se por possuir uma formação alicerçada em princípios deliberados, e, portanto, aprendidos de maneira intencional em cursos de formação universitária com garantia de uma diplomação, que possibilita o título de profissional ao fim de uma jornada de estudos (CARBONEAU, 2006; BOURDOUNCLE, 2006). 
A terceira característica de uma profissão é o exercício autônomo, ético e responsável. Com efeito, a autonomia no exercício profissional deve estar fundamentada na ética formalizada mediante um código deontológico. Portanto, a profissão deve ter por obrigatoriedade prestar responsabilidades pelos possíveis usos inadequados dos conhecimentos profissionais ofertados, de modo a responder aos danos que possam ser causados aos seus clientes (CARBONEAU, 2006; BOURDOUNCLE, 2006).

Por último, a quarta característica de uma profissão é a inserção do profissional no mercado de trabalho por meio da mediação de uma associação, ordem ou organização. Esses setores devem ter por obrigatoriedade supervisionar a formação, deliberar sobre os processos de autorização para atuação dos seus membros, construir e definir um código de ética e criar mecanismos de controle que garantam a especificidade da profissão e dos seus membros (CARBONEAU, 2006; BOURDOUNCLE, 2006).

Ao analisarmos a atividade docente na Educação Superior, percebemos que ela não se enquadra em todas as categorias anteriormente anunciadas, o que nos leva a questionar: seria a docência universitária uma semiprofissão? Para respondermos esse questionamento, recorremos à Tardif (2009), quando problematiza as especificidades da atividade docente no âmbito universitário, questionando se ela se constitui, verdadeiramente, uma profissão:

As universidades não pedem, aos futuros professores, para provar que possuem conhecimentos especializados, principalmente em pedagogia, didática, avaliação. Também não exigem que eles tenham conhecimentos especializados em matéria de relações interpessoais "professor/estudante", de apoio ao desenvolvimento, ou de avaliação da aprendizagem. (TARDIF, 2009, p. 61).

Para Corrêa et al. (2011, p. 80), a dimensão dos processos investigativos se sobrepõe aos processos de ensino na universidade, 
ficando negligenciados os conhecimentos do campo didático e pedagógico, o que faz, consequentemente, que os professores da Educação Superior "nem sempre apresentem atributos específicos, necessários e desejados para a vertente docente dessa profissão". Porém, a atividade docente deve ser concebida como uma ação especializada, o que pressupõe a necessidade de compreendê-la no bojo de uma perspectiva profissional. Tal aspecto vai de encontro a uma visão amadora e vocacional da profissão de professor, que contraria a ideia defendida por muitos autores como D'Ávila (2013): para o exercício da docência é necessário um conjunto de habilidades e conhecimentos próprios da profissão, para que se eleve a qualidade do seu desempenho.

Vale acrescentar que para a regulação da profissão docente, autores como D'Ávila; Soneville (2008) e Rios (2009), entre outros, acordam sobre a necessidade da construção de um código deontológico para que os próprios professores tenham controle sobre os seus processos de atuação profissional, como a entrada, a progressão e a permanência na profissão, ou seja, o estabelecimento de princípios reguladores no que se refere aos aspectos sociais e éticos que devem orientar a profissão, a fim de que esses sujeitos mantenham uma coerência nas atitudes e posturas assumidas em sua prática profissional.

Todavia, como destaca Bourdoncle (2006), a questão do código deontológico não é consensual. Segundo Seiça (2003), existem aqueles teóricos que se opõem à sua criação no âmbito da profissão docente, considerando necessária uma maior reflexão sobre essa questão, tendo em vista que o referido código poderia impor condicionamentos nas decisões dos professores.

Vale acrescentar que a questão da profissão docente tem sido combatida por alguns grupos que defendem que o professor ficaria submetido ao controle do governo que intenciona "[...] alinhar os sistemas de ensino às transformações que o sistema capitalista mundial vem enfrentando" (CAMARGO; HAGE, 2004, p. 272). Tal controle seria necessário, tendo em vista que os professores assumem um papel estratégico para o desenvolvimento do país e para a competitividade 
internacional, na medida em que cabe a ele a formação de cidadãos qualificados para o mundo do trabalho.

Posto isto, concluímos que o conceito de profissão de professor apresenta controvérsias e limitações, visto que a docência possui características, especificidades e dinâmicas próprias, não se enquadrando, portanto, no conceito de profissão utilizado para se referir a outras categorias.

Sendo assim, e considerando a oscilação e os aspectos dinâmicos da docência, o termo profissionalidade parece ser o mais adequado, o que vai divergir do sentido estático das profissões liberais clássicas (CUNHA, 2005). Além disso, o conceito de profissionalidade abarca a complexidade da docência, um conjunto de saberes, atitudes, valores, habilidades e competências necessárias ao seu exercício, construídos coletivamente, que se corporificam no ambiente do trabalho, considerando o contexto político, social e histórico, tendo a prática docente como centro da construção da profissão docente.

Para a compreensão do sentido da profissionalidade docente, Roldão (2005) apresenta quatro critérios: 1) reconhecimento da especificidade que caracteriza a atividade profissional, 2) saber específico que constitui o desenvolvimento da atividade profissional e sua natureza, 3) poder de decisão e autonomia sobre o trabalho que é desenvolvido, 4) e pertença a um grupo específico que possui um saber, o partilha, regula e defende.

Diante do exposto, evidenciamos que a profissionalidade é uma construção que acontece durante toda a vida do sujeito, na medida em que "[...] se pensa e se experimenta, produzindo um modo de ser singular" (MOROSINI, 2006, p. 400). Neste sentido, é a subjetividade que faz a diferença e não um padrão externo, um modelo a ser seguido, que traz a ideia de equilíbrio, de estabilidade. Ao contrário, a profissionalidade é um estado em risco de desequilíbrio permanente (MOROSINI, 2006).

Em síntese, o termo profissão docente designa uma atividade profissional especializada, específica e complexa e aproxima- 
se mais do termo profissionalidade, na medida em que é um processo, uma construção que depende muito da subjetividade de cada professor.

\section{Metodologia}

Apresentaremos, nesta parte do texto, o percurso metodológico que norteou o desdobramento da pesquisa-ação colaborativa durante o primeiro ano do seu desenvolvimento. Sua finalidade é a concretização de uma proposta de formação continuada que visa incentivar o desenvolvimento profissional de professores universitários de uma instituição de Educação Superior pública do Estado da Bahia.

De abordagem metodológica qualitativa, a pesquisaação colaborativa, no campo da formação de professores, objetiva possibilitar às instituições educacionais o fortalecimento e a construção de comunidades críticas e emancipadoras. Os seus procedimentos metodológicos garantem que os estudos e a formação sejam elaborados a partir das demandas da prática educativa, que pode ser modificada; é realizada a partir dos princípios de planejamento, observação, ação, reflexão e nova ação; acontece de modo colaborativo, ou seja, implica a influência de pesquisadores e pesquisados nas tomadas de decisões (IBIAPINA, 2008).

Contando com a participação de 9 professorespesquisadores, a pesquisa que empreendemos teve por objetivo conhecer as representações de professores-pesquisadores sobre a profissão docente. Eles são produtores de conhecimento sobre as suas próprias práticas educativas, motivo pelo qual têm se implicado nesse processo formativo, de forma espontânea. As reuniões quinzenais, que duram aproximadamente 3 horas, são planejadas conjuntamente a partir de temáticas que emergem do cotidiano das práticas educativas desses profissionais. Os testemunhos foram filmados e gravadas em aparelhos eletrônicos e, posteriormente, transcritos. Todos assinaram o termo de consentimento livre e esclarecido. Para preservar a identidade desses colaboradores, usamos a consoante $\mathrm{P}$, seguida de um numeral. 
Quadro 1- Características dos professores-colaboradores

\begin{tabular}{|c|c|c|}
\hline Colaborador & $\begin{array}{c}\text { Anos de exercício } \\
\text { na docência }\end{array}$ & Maior titulação acadêmica \\
\hline P1 & 29 anos & Doutorado em Ciências Fisiológicas \\
\hline P2 & 18 anos & Doutorado em Astronomia \\
\hline P3 & 15 anos & $\begin{array}{c}\text { Doutorado em Biologia Celular e } \\
\text { Molecular }\end{array}$ \\
\hline P4 & 18 anos & Doutorado em Química \\
\hline P5 & 27 anos & $\begin{array}{l}\text { Doutorado em Desenvolvimento } \\
\text { Sustentável }\end{array}$ \\
\hline P6 & 17 anos & Doutorado em Educação \\
\hline P7 & 9 anos & Mestrado em Ciências de Alimentos \\
\hline P8 & 19 anos & Mestrado em Literatura \\
\hline P9 & 23 anos & Doutorado em Química Orgânica \\
\hline
\end{tabular}

Fonte: Elaborado pelos autores.

Para a análise dos materiais produzidos, nos inspiramos na técnica análise de conteúdo (BARDIN, 2006).

\section{Análise dos dados de representações de professores-pesquisadores sobre a profissão docente}

Com o objetivo de organizar os dados produzidos de uma maneira mais alinhada possível ao foco do recorte adotado nesta pesquisa, a profissão docente, realizamos a leitura atenta do material transcrito, definindo subcategorias e unidades de sentidos, que nos ajudaram a compreender mais profundamente as perspectivas e representações dos professores-colaboradores à luz do referencial teórico adotado. 
Partindo dos dados produzidos, buscamos identificar unidades de sentido e, na sequência, agrupamos os depoimentos dos sujeitos a partir dos aspectos que têm em comum, analisando e interpretando tais achados empíricos com base no quadro referencial. Assim, definimos duas categorias: a) Docência universitária: Prática baseada no saber artesão; b) Ofício aprendido na prática e com os pares.

Docência universitária: prática baseada no saber artesão

As análises das representações dos professores indicam que a docência universitária é realizada sem um norteamento específico da natureza dos conhecimentos didáticos e pedagógicos que fundamentam a educação e as destrezas, conhecimentos e saberes científicos do metier dessa profissão, aspectos que constituem a profissionalidade docente. Os relatos de $\mathrm{P} 4$ e $\mathrm{P} 2$ elucidam estes aspectos:

[...] Eu confesso a vocês que eu não sei o que vou fazer [...] E aí, eu fico me questionando: que prática eu posso colocar, se eu não tenho uma luz que me oriente [...] Eu não sou, eu não entendo das questões teóricas, dos estudiosos no assunto [...]. (Depoimento de P4, Informação verbal).

[...] Porque é muito intuitivo, assim, eu nunca li nada

[...] você sabe... eu nunca li nada de nenhum autor

[...] Eu não tenho uma leitura, eu sei alguma coisa

de Paulo Freire, muito pouquinho também, né? (Depoimento de P2, Informação verbal, grifo nosso).

Aparecem explicitamente nos enunciados anteriores, 0 reconhecimento de necessidades formativas e lacunas no domínio dos aspectos que embasam a prática docente, a fim de que os professores possam compreender os processos de aprendizagem e de avaliação dos estudantes, além de ajudar os próprios docentes na reflexão sobre o desenvolvimento de suas práticas educativas. Articulando estes dados com as proposições expostas por Bourdoncle (2006) e Carboneau (2006) sobre a necessidade do domínio de um conjunto de conhecimentos especializados que se traduzem na oferta de um serviço específico, 
como uma das características de uma profissão, podemos inferir que se a formação dos aspectos pedagógicos e didáticos não se fazem presentes na formação profissional dos sujeitos da pesquisa, e eles podem exercer a docência de forma intuitiva, sem saber o que vão fazer, a profissão de professor não passa de um ofício que pode ser desenvolvido por qualquer sujeito.

Ora, essa ideia é defendida por Tardif (2009, p. 61), ao afirmar que as atividades docentes nas universidades não são percebidas nem concebidas como uma profissão. Nas palavras do autor as instituições "[...] não pedem, aos futuros professores, para provar que possuem conhecimentos especializados antes de assumir [...] responsabilidades nesse setor de trabalho". Há, perceptivelmente, um habitus ${ }^{3}$ estabelecido nos diversos ambientes acadêmicos, que desconsideram, ou mesmo repudiam a necessidade de formação pedagógica do seu professorado.

Nessa direção, reflexões teóricas trazidas por D’Ávila (2013) indicam a evidência de problemáticas na formação de muitos dos profissionais que atuam no ensino universitário, em sua maioria, oriundos de vários campos de conhecimento e que nunca tiveram contato com os estudos pedagógicos. Estes problemas vão desde aspectos ligados às dimensões epistemológicas e filosóficas, até os procedimentos didáticos, metodológicos e psicopedagógicos. Para a autora, tais implicações são derivadas, dentre outras questões, por uma falta de preparo para o exercício das funções docentes em sala de aula. Corroboramos com essas posições anteriormente delineadas, e ainda acrescentamos a negligência, por parte dos textos legais brasileiros que silenciam sobre a necessidade de profissionalização da docência nesse segmento, ainda que uma vasta produção acadêmica já aponte essa fragilidade.

Em nosso entender, as consequências de tais hiatos na formação dos professores universitários se reverberam nos processos de

3 O conceito de habitus é aqui compreendido na perspectiva de Bourdieu que o define como "um sistema de disposições aberto, permanentemente afrontado a experiências novas e permanentemente afetado por elas. Ele é durável, mas não imutável". 
ensino que desenvolvem e incidem em fortes influências no processo de aprendizagem dos estudantes, visto que, os professores necessitam conhecer como a aprendizagem do adolescente e adulto se processa, como motivá-lo para o estudo dos componentes curriculares e como desenvolver estratégias adequadas para sua efetivação.

Nesta perspectiva, o depoimento de P1, a seguir, anuncia a maneira como procura interagir com os estudantes, buscando proporcionar a participação desses sujeitos e o seu entrosamento na sala de aula. Todavia, percebemos que esse professor mobiliza, basicamente, o saber da experiência, que fora adquirido ao longo dos 18 anos de exercício profissional.

Sem dúvidas, o saber da experiência é imprescindível para o desenvolvimento da práxis educativa. Tal saber faz parte da tríade (experiência, conhecimento, saberes pedagógicos e didáticos) anunciada por Pimenta (2012) relativa aos conhecimentos que devem possuir os professores e que constituem a sua identidade profissional. Todavia, o saber da experiência por si só, não basta, é frágil para explicar as realidades e complexidades que se apresentam na sala de aula universitária. Com efeito, encontramos apoio nas ideias de Pimenta e Almeida (2011), para quem o ensino é uma atividade com características e destrezas próprias, e, por isso, pressupõe a necessidade de uma formação voltada, exclusivamente, para esse fim. Sendo assim, torna-se crucial o saber savant, quer dizer, o saber científico adquirido nas disciplinas que contribuem com o campo da educação, como a Psicologia, a Sociologia, a Filosofia, dentre outras, que, se bem tratadas, poderiam ajudar a responder as problemáticas da sala de aula (VAN DER MAREN, 1993).

O depoimento a seguir revela o quanto as atitudes do professor em sala de aula são baseadas na intuição:

Quando eu interajo com o aluno [...] Eu acho que ele está pensando assim, acho que essa interação vai ser melhor, aí eu pergunto. Se ele responde, se ele acha que aquela ideia é legal, então a gente continua a 
desenvolver o trabalho. Se não, eu encontro né [...]. Então isso [...] foi uma coisa intuitiva. (Depoimento de P1, Informação verbal, grifo nosso).

No processo de profissionalidade, vimos que a prática docente depende muito da subjetividade do professor. Ora, a intuição não tem sido contemplada como um saber, por ser um saber diferente do saber savant. Esse saber do senso comum, chamado por Van der Maren (1993) de "saber artesão", é um saber que se possui, que se executa, mas que é desqualificado pelas ciências da educação porque não produz discurso e, portanto, não fundamenta uma profissão. É um saber partilhado por aqueles que dominam determinado métier, mas ele não se formaliza, não se explica, ele se vê, se copia, se sente, se aprende na ação. Ele explica a ação pela beleza, pelo prazer, pelo gesto, pelo costume. Destarte, tal saber sozinho não dá conta da complexidade da prática docente na atualidade.

No discurso do docente, fica explícito o desejo de inovar sua prática e de romper, inclusive, com o paradigma que a fundamenta. Evidenciamos o esforço desse sujeito em desenvolver um trabalho que tenha novos sentidos. $O$ professor processa essa mudança a partir da reflexão sobre a ação, no momento em que examina o que se passa na ação, os sinais dados pelos estudantes: "depois que eu descobri que é uma coisa intuitiva". Com efeito, Van der Maren (1993) assegura que uma práxis retrospectiva constitui uma das bases fundamentais do saber profissional:

Então, assim, é uma coisa mesmo intuitiva [...] Depois que eu descobri que é uma coisa intuitiva... é você que tem de mudar os seus paradigmas de trabalho. Romper: não, eu não vou mais aplicar a prova do jeito tradicional, não é assim, eu vou querer que o aluno pense assim, assim e assado, é nessa quebra de paradigma que foi mais fácil [...]. Eu percebi que não era por aí [...]. (Depoimento de P1, Informação verbal, grifo nosso). 
Paralelo a estes elementos anteriores, o depoimento de $\mathrm{P} 4$ revela a inconsistência da sua formação teórica para assegurar o norteamento de ações que possa desenvolver com segurança no cotidiano da sala de aula: "[...] é só uma coisa que eu penso, não tenho embasamento teórico para defender nada disso [...]" (Depoimento de P4, Informação verbal).

Assim, é perceptível que os excertos anteriormente mencionados nos revelam a distância entre a concepção de formação idealizada pelos pesquisadores do campo da pedagogia universitária, com a realidade vivida na docência na educação superior. Há uma fragilidade explícita no domínio dos conhecimentos didáticos e pedagógicos que precisa ser revista.

\section{Ofício aprendido na prática e com os pares}

Outro elemento que podemos destacar nos discursos dos professores é o reconhecimento de que, somente o domínio dos conteúdos das disciplinas específicas que ministram, por si só, não garante o sucesso dos processos de ensino que propõem e gerenciam. Esse reconhecimento só passa a acontecer na prática, no contexto das suas atuações profissionais, visto que grande parte deles não teve uma formação inicial no campo da docência, dificultando a reflexão sobre estes aspectos.

O depoimento de P5, engenheira de formação, com 27 anos de exercício na docência expõe como no início de sua atuação profissional entendia ser necessário dominar, somente, o conteúdo específico das disciplinas sob sua responsabilidade. Porém, ela mesma indica que, somente esse conhecimento não é suficiente, caso não consiga ser transposto didaticamente no processo de ensino e aprendizagem e se transforme em conhecimento construído pelos estudantes. Observemos o excerto a seguir:

Eu digo que quando eu comecei a ensinar, eu sou engenheira, eu tinha que saber de Química, mil toneladas... E eu achava que isso era suficiente. 
Tudo bem, isso é bom. Todas as duas toneladas de Química não vale nada, se você não consegue transmitir essa Química em ensino [...]. (Depoimento de P5, Informação verbal, grifo nosso).

Notamos que o depoimento da professora vai ao encontro das defesas realizadas por Mizukami et al. (2010) sobre a necessidade de que os professores dominem uma base de conhecimentos profissionais para o ensino. Quando P3 refere-se à necessidade de "transmitir Química em ensino" ela está colocando, ainda que de forma implícita, a necessidade deque o professor domine o conhecimento didático do conteúdo, que são "[...] os aspectos do conteúdo mais relevantes para serem ensinados [...] as representações mais úteis de tais ideias, as analogias mais poderosas, ilustrações, exemplos, explanações, demonstrações [...]" (SHULMAN, 1986, p. 9 apud MIZUKAMI et al., 2010, p. 69).

O discurso revela, ainda, o quanto foi aprendendo a desenvolver suas atividades docentes a partir da sua experiência profissional, e como isso tem lhe possibilitado avançar em processos de aprendizagem da docência: "Então, não teve jeito, tem três anos que eu ensino e de lá pra cá eu aprendi muito. [...] Eu estava pensando, eu vou dar aula teórica amanhã pela manhã, o que é que eu vou fazer com esse povo?" (Depoimento de P3, Informação verbal).

Diante dessa situação, algumas questões emergem: em que modelo pedagógico e seus fundamentos epistemológicos estaria se baseando P5 para desenvolver suas atividades profissionais? Ela desenvolve um papel protagonista no seu processo de desenvolvimento profissional docente. No contexto de nossa pesquisa, percebemos que a intuição e a socialização de dilemas da prática com outros profissionais são os principais mecanismos desencadeadores dessas aprendizagens.

Nessa direção, nos apoiamos nas ideias de Benedito et al. (1995, p. 31) quando afirma que "[...] o professor universitário aprende a sê-lo mediante um processo de socialização em parte intuitiva, 
autodidata [...] seguindo a rotina dos 'outros'. Isso se explica, sem dúvida, devido à inexistência de uma formação específica como professor universitário".

Destarte, acreditamos que a capacidade autodidata do professor em colocar-se como sujeito protagonista do seu agir é relevante, porém, insuficiente para desconstruir as representações que edificaram com suas próprias experiências vividas quando estudantes, sobre o papel do professor, conforme pontua Gauthier et al.(2006). Seria necessária uma formação que, partindo da prática, chegasse à teoria, avançando no sentido de melhorá-la e de desenvolver-se profissionalmente.

Notamos, ainda, que a socialização e a troca de experiências com outros colegas de profissão são mecanismos que ajudam os docentes participantes da pesquisa-ação colaborativa a reavaliarem a sua atuação e buscarem modificá-la, como expresso neste discurso:

\footnotetext{
[...] e aí quando eu comecei, a professora anterior me deu uma dica que eu acho super importante sobre esse tema de complexidade progressiva. Ela falou: não pontue apenas o trabalho final. Vá cobrando e vá dando o feedback, porque se você deixar tudo, no final, faltando quinze dias para o semestre acabar, você recebe um texto e está péssimo, e aí? Você não conseguiu acompanhar o processo, e aí? E assim eu fiz. E funcionou muito bem. (Depoimento de P7, Informação verbal, grifo nosso).
}

Desse modo, percebemos que a troca de experiências com outros colegas de profissão, são alguns elementos que vão ajudando os professores universitários, participantes da pesquisa-ação colaborativa, a construírem os seus saberes da profissão docente. No que pese o valor de tais experiências protagonistas dos professores em suas atividades profissionais, notamos, porém, o indicativo de uma fragilidade nos conhecimentos didáticos e pedagógicos que orientem uma ação docente qualificada. 


\section{Considerações finais}

Mostramos no início deste texto as diversas transformações mundiais e nacionais que se reverberam em novas exigências e implicações para a profissão docente na Educação Superior no limiar da contemporaneidade.

Realizamos uma análise teórica sobre o conceito de profissão e as características próprias que a definem. Buscamos, também, compreender as suas implicações para a análise do trabalho de professores que atuam no segmento universitário. Notamos, assim, que o conceito de profissionalidade se adéqua mais às características do trabalho docente, que está sempre em movimento, aspecto que a diferencia das características das profissões liberais.

No que concerne aos achados da empiria, a análise sobre as representações dos professores desvelam que a docência universitária é realizada sem um norteamento específico da natureza dos conhecimentos pedagógicos e didáticos. Além disso, visualizamos lacunas e necessidades formativas relacionadas à natureza do processo de ensino e aprendizagem que possam ajudá-los a refletir sobre o desenvolvimento de suas práticas educativas.

Ainda nesse contexto, notamos que os docentes mobilizam, basicamente, o saber da experiência, que fora adquirido ao longo dos anos de exercício do magistério superior para desenvolver as suas atividades profissionais. Assim, suspeitamos que a socialização profissional seja um dos principais mecanismos desencadeadores dos processos de aprendizagem da profissão docente. Todos estes indícios revelam que a profissionalidade docente vai acontecendo no processo, de forma dinâmica e não linear, sem formação inicial que, como em outras profissões liberais, consolide a profissão de professor universitário.

Tomando por base tal situação, consideramos necessário o investimento em políticas institucionais para a formação didáticopedagógica do corpo docente, estimulando o desenvolvimento profissional desses sujeitos na perspectiva da constituição da 
profissionalidade, entendida enquanto um conjunto de conhecimentos, saberes e atitudes que caracterizam a atividade docente, conforme propõe Roldão (2005). Tais políticas devem valorizar, no processo de progressão na carreira do magistério, a docência, fomentando, inclusive, o desenvolvimento de pesquisas sobre a prática docente e organizando colóquios, rodas de conversa, congressos e seminários onde os professores possam apresentar e discutir com os pares as inovações implantadas com sucesso em seu métier.

Além disso, corroboramos algumas estratégias anunciadas pela Rede Inter-Regional Norte, Nordeste e Centro Oeste sobre Docência na Educação Superior (RIDES), que tem reunido pesquisadores do campo da pedagogia universitária a cada dois anos, a fim de apresentar e discutir resultados de estudos, redigir manifestos e declarações para organismos governamentais e não governamentais e propor ações, estudos mais amplos e políticas que fortaleçam a formação de docentes para atuarem na Educação Superior, como as estratégias:

- Alteração do termo "preparação" para formação docente no texto da Lei de Diretrizes e Bases (LDB 9394/96);

- Regulamentação e instituição da exigência de formação inicial e continuada para professores universitários, estabelecendo disciplinas obrigatórias que tenham como foco a docência universitária nos programas de pós-graduação stricto sensu, em nível de mestrado e doutorado.

Ressaltamos os passos substanciais que têm dado a pesquisa "Inovação da Prática Pedagógica de Professores do Ensino Universitário pela Pesquisa-ação Colaborativa" no sentido de possibilitar que os professores-pesquisadores discutam com seus pares os dilemas da prática, aprofundem conhecimentos teóricos sobre os processos de aprendizagem e motivação dos estudantes da graduação, desenvolvam estratégias ativas de ensino-aprendizagem fundamentadas em uma epistemologia que considere o sujeito da aprendizagem com as suas idiossincrasias, construa parceria com os pares na direção da superação 
do individualismo e do isolamento da sala de aula, a fim de enfrentar a realidade circundante, e troquem experiências sobre as inovações que têm introduzido no exercício profissional.

Nesse sentido, vale destacar que os colaboradores da pesquisa, embora revelem que desenvolviam suas práticas de forma artesanal e intuitiva, mostram que deram passos significativos na direção da profissionalidade, na medida em que desvelam suas dúvidas em lidar com a complexidade da docência na atualidade, mostram-se abertos a estudarem e a pesquisarem sobre suas práticas, buscando compreendêlas e superar os seus limites. Por fim, vale destacar que esses sujeitos comunicam os avanços que têm experimentado e exploram, com a ajuda do coletivo, uma nova epistemologia que fundamente a sua prática e dê conta da aprendizagem dos estudantes, elevando a qualidade do trabalho que desenvolvem.

\section{Referências}

BARDIN, L. Análise de conteúdo. Lisboa: Edições 70, 2006.

BENEDITO, Viença et al. A formação universitária em debate. Barcelona: Universidade de Barcelona, 1995.

BOURDONCLE, Michel. Modelos de formação e profissionalização do ensino: análise crítica de tendências norte-americanas. Revista da FAEEBA: Educação e contemporaneidade, Salvador, v. 1, n. 1, jan./jun. 2006.

BRASIL. A democratização e expansão da educação superior no país 2003 - 2014. 2014. Disponível em:<http://portal.mec.gov.br/>. Acesso em: 20 jan. 2016

CAMARGO, Arlete Maria M. de; HAGE, Salomão M. A política de formação de professores e a reforma da educação superior. In: MANCEBO, Deise; FÁVERO, Maria de Lourdes A. (Org.). Universidade: políticas, avaliação e trabalho docente. São Paulo: Cortez, 2004.

CARBONEAU, Michel. La profissionnalisation des enseignantes; analyse 
ssociologique sanglaises et anglaises et américains. Revue dês sciences de l’education, v.19, n. 1. 2006.

CORRÊA, A. K. et al. Processos formativos de docentes universitários: aspectos teóricos e práticos. In: PIMENTA, S. G; ALMEIDA, M. I. de (Org.). Pedagogia Universitária: caminhos para a formação de professores. São Paulo: Cortez, 2011.

CUNHA, M. I. da (Org.). Formatos avaliativos e concepção de docência. Campinas, SP: Autores Associados, 2005.

D'ÁVILA, C. M. Docência na educação superior: labirintos e saídas na construção da profissionalidade docente. In: D’ÁVILA, C. M.; VEIGA, I. P. A. Profissão docente na educação superior. Curitiba, PR: CRV, 2013.

D'ÁVILA, C. M; SONEVILLE, J. Trilhas percorridas na formação de professores: da epistemologia da prática à fenomenologia existencial. In: VEIGA, I. P. A; D’ÁVILA, C. M. (Org.). Profissão docente: novos sentidos, novas perspectivas. Campinas, SP: Papirus, 2008.

D. SOBRINHO, J. Professor universitário: contextos, problemas e oportunidades. In: CUNHA, M.I. da; SOARES, S. R; RIBEIRO, M. L. (Org.).Docência Universitária: profissionalização e práticas educativas. Feira de Santana: UEFS Editora, 2009.

FREIRE, Paulo. Professora sim, tia não: cartas a quem ousa ensinar. São Paulo: Olho D'água, 1997.

GAUTHIER et al. Por uma teoria da Pedagogia: pesquisas contemporâneas sobre o saber docente. 2. ed. Ijuí: Editora Unijuí, 2006.

IBIAPINA, Ivana Maria. Pesquisa colaborativa: investigação, formação e produção de conhecimentos. Brasília, DF: Ed. Liber Livro, 2008.

JOHNSON, Allan. Dicionário de Sociologia. Rio de Janeiro: Jorge Zahar Ed, 1997.

MOROSINI, Marília C. Enciclopédia de Pedagogia universitária. Brasília, DF: INEP/RIES, 2006.

MIZUKAMI, M. da G. N. et al. (Org.). Escola e aprendizagem da docência: processos de investigação e formação. São Carlos: EDUFScar, 2010. 
MOROSINI, M. (Ed.). Enciclopédia de pedagogia universitária: glossário. Brasília, DF: INEP, 2006.

PIMENTA, S. G. Formação de professores: identidade e saberes da docência. In: PIMENTA, S. G. (Org.).Saberes pedagógicos e atividade docente. 8. ed. São Paulo: Cortez, 2012.

PIMENTA, S. G. ALMEIDA, M. I. (Orgs.). Pedagogia Universitária: caminhos para a formação de professores. São Paulo: Cortez, 2011.

RIOS, T. A. Ética na docência universitária: apontamentos para um diálogo. In: CUNHA, M. I. da; SOARES, S. R; RIBEIRO, M. L. (Org.).Docência Universitária: profissionalização e práticas educativas. Feira de Santana: UEFS Editora, 2009.

ROLDÃO, Maria do Céu. Formação de professores, construção do saber profissional e cultura da profissionalização: que triangulação? In: ALONSO, Luísa; ROLDÃO, M. Céu (Org.). Ser professor de $1^{\circ}$ ciclo construindo a profissão. Braga: CESC, 2005.

SEIÇA, A. B. A docência como práxis, ética e deontologia: um estudo empírico. Lisboa: Ministério da Educação, 2003.

SOARES, S. R; CUNHA, M. I. da. Formação do professor: a docência universitária em busca de legitimidade. Salvador: EDUFBA, 2010.

TARDIF, J. Se o professorado universitário fosse uma profissão... In: CUNHA, M.I.da; SOARES, S. R; RIBEIRO, M.L. (Org.).Docência Universitária: profissionalização e práticas educativas. Feira de Santana: UEFS Editora, 2009.

VAN DER MAREN, Jean-Marie. Savoir senseignantse tprofessionnalisation de l'enseignement. Revue des sciences de l'éducation, v. 19, n. 1, p. 153-172, 1993. 